\title{
Monochromated EELS and Optical Spectroscopy of Layered Carbon Nitrides
}

\author{
Diane M. Haiber ${ }^{1}$ and Peter A. Crozier ${ }^{1}$ \\ 1. School for Engineering of Matter, Transport \& Energy, Arizona State University, Tempe, Arizona \\ 85287-6106, USA
}

Layered carbon nitride materials, including graphitic carbon nitride $\left(\mathrm{g}-\mathrm{CN}_{\mathrm{x}} \mathrm{H}_{\mathrm{y}}\right)$ and poly(triazine imide) with intercalated $\mathrm{Li}$ and $\mathrm{Cl}$ ions $(\mathrm{PTI} / \mathrm{LiCl})$, are emergent materials for energy-related applications including solar water splitting and "postsilicon" electronics $[1,2]$. Synthesis of $\mathrm{g}-\mathrm{CN}_{\mathrm{x}} \mathrm{H}_{\mathrm{y}}$ and PTI/LiCl involves specific pyrolysis routes that achieve heptazine $\left(\mathrm{C}_{6} \mathrm{~N}_{7}\right)$ and triazine $\left(\mathrm{C}_{3} \mathrm{~N}_{3}\right)$ based structural motifs, respectively, with varying degrees of amine bridging-groups owing to incomplete condensation. Due to their polymeric nature, it is likely that a range of defects in addition to amine content contribute to their optoelectronic properties. A fundamental understanding between structure and defects' relationship to functionality will lead to rational engineering of these materials for efficient photocatalytic hydrogen production. Traditional optical characterization techniques, including infrared/visible/UV absorption and Raman scattering spectroscopy, are limited in the sense that they contain bulk-averaged signals. By employing monochromated electron energy-loss spectroscopy (EELS) with an aloof-beam geometry, vibrational modes and interband transitions can be probed on the nanoscale without damaging these beam-sensitive materials [3].

To determine the molecular species present with high spatial resolution, several vibrational EEL spectra (vibEELS) were acquired with a $2 \mathrm{meV} / \mathrm{ch}$ dispersion and approximate energy resolution (measured in the vacuum) of $16 \mathrm{meV}$. The bandgap energies were also measured in the valence-loss region using a dispersion of $5 \mathrm{meV} / \mathrm{ch}$ and corresponding energy resolution of $\sim 25 \mathrm{meV}$. All EEL spectra were collected at $60-\mathrm{kV}$ on a Nion UltraSTEM-100 using a convergence angle of 12 mrad. For g- $\mathrm{CN}_{\mathrm{x}} \mathrm{H}_{\mathrm{y}}$, a commercial powder ("Nicanite") was obtained from Carbodeon Ltd. and synthesis of PTI/LiCl powder was performed according to Schwinghammer et al [4]. Samples for EELS were prepared by immersing lacey-C grids in aqueous dispersions of the powders after ultrasonicating for 40 minutes. Bulk optical spectroscopic techniques including UV-Vis diffuse reflectance, FTIR absorption, and FT-Raman $\left(\lambda_{\text {excitation }}=1064 \mathrm{~nm}\right)$ spectroscopy were also collected as a means for interpreting low-loss EEL spectra.

Several vibEEL spectra taken from outside the $\mathrm{g}-\mathrm{CN}_{\mathrm{x}} \mathrm{H}_{\mathrm{y}}$ and $\mathrm{PTI} / \mathrm{LiCl}$ samples exhibit two major features centered at around 170 and $400 \mathrm{meV}$. Figure 1(a) displays these vibEELS "fingerprints" of heptazine- and triazine-based carbon nitrides; all were acquired with an impact parameter of $\sim 4 \mathrm{~nm}$. Variations in the vibEELS signal (spectra 2 and 4) are characterized by the presence of a very weak, additional peak at $\sim 265 \mathrm{meV}$, which is believed to be due to small amounts of double/triple bonded carbon. From the FTIR absorption spectra, the vibEELS can be directly interpreted as containing excitations of $\mathrm{C}-\mathrm{N}$ ring stretch/bending modes (140-200 meV) and $\mathrm{N}-\mathrm{H}$ stretching modes (370-410 $\mathrm{meV})$. An FT-Raman spectrum was also collected from the $\mathrm{g}-\mathrm{CN}_{\mathrm{x}} \mathrm{H}_{\mathrm{y}}$ powder. Figure $1(b)$ shows the raw FTIR and FT-Raman spectra from the $\mathrm{g}-\mathrm{CN}_{\mathrm{x}} \mathrm{H}_{\mathrm{y}}$ (heptazine-containing) sample. To simulate the effect of the EEL spectrometer energy resolution, the bulk optical spectra from $\mathrm{g}-\mathrm{CN}_{\mathrm{x}} \mathrm{H}_{\mathrm{y}}$ were convolved with a Gaussian of FWHM=16 meV. A comparison between the resulting spectra, all with the backgrounds subtracted, is found in Figure 1(c). Using aloof-beam valence EELS as a probe (Fig.2(a)), the bandgap energies of three different layered carbon nitrides were found to be between 2.7-3.1 eV. The KubelkaMunk diffuse reflectance spectra $\left(f(R)=(1-R)^{2} / 2 R\right)$, commonly used for determining the UV-Vis 
absorption of highly scattering powders, is quite different from EELS in that a 2.5-eV absorption feature is not observed in the later. Figure 2(b) shows the experimental UV-Vis absorption spectra from the three different carbon nitride powders that were also measured with valence EELS. A table displaying the similarity in bandgap energies derived from the valence EELS and UV-Vis absorption spectra are summarized in Figure 2(c). A detailed interpretation of low-loss EELS, in the context of related bulk/optical spectroscopies, will be presented for the graphitic carbon nitride system with an overall goal of connecting the dots between nanoscale defects and functionality for photocatalytic water reduction.

\section{References:}

[1] S. Cao et al. Adv. Mater. 2015, 27, 2150-2176.

[2] M.J. Bojdys. Macromol. Chem. Phys. 2016, 217, 232-241.

[3] D.M. Haiber et al. Microsc. Microanal. 2016, 22 (Suppl 3), 986-987.

[4] K. Schwinghammer et al. J. Am. Chem. Soc. 2014, 136, 1730-1733.

[5] The support from the U.S. DOE (DE-SC0004954), use of AC-TEM at John M. Cowley Center for High Resolution Electron Microscopy, and use of synthesis/characterization facilities within the LeRoy Eyring Center for Solid State Science at Arizona State University are acknowledged. The contribution of Dr. Toshi Aoki in EELS acquisition and training on the Nion microscope is also acknowledged.
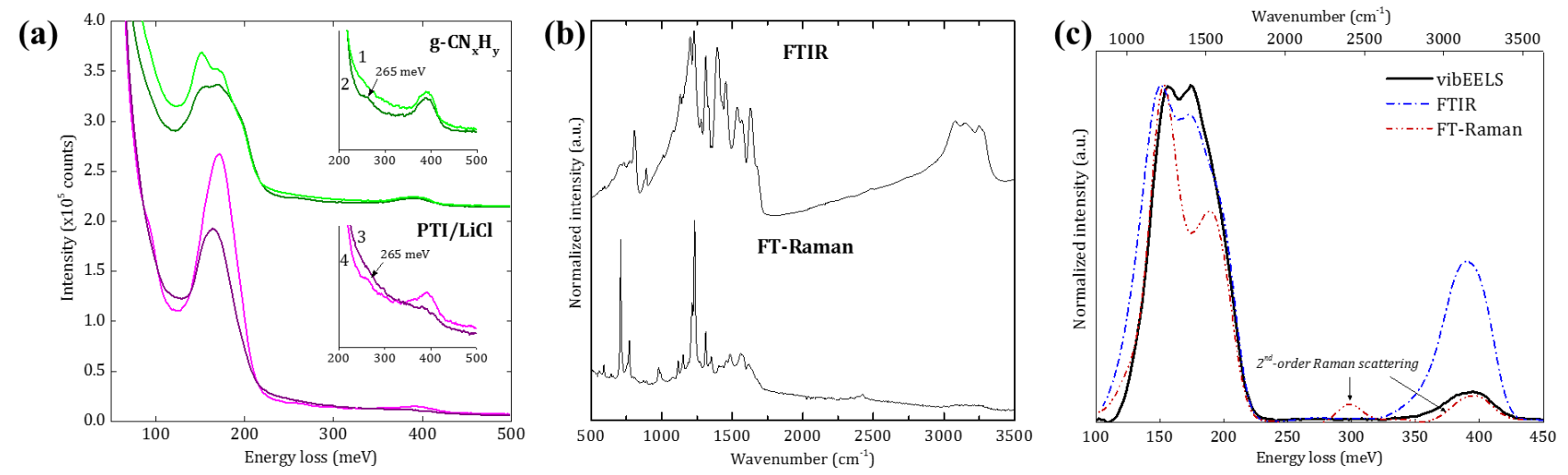

Figure 1. (a) Typical vibEELS from g- $\mathrm{CN}_{x} \mathrm{H}_{y}$ and PTI/LiCl. (b) Raw FTIR and FT-Raman spectra from g- $\mathrm{CN}_{\mathrm{x}} \mathrm{H}_{\mathrm{y}}$. (c) Processed FTIR and FT-Raman (background-subtracted, convolved with a Gaussian of FWHM=16 meV) compared to the (background-subtracted) vibEELS signal for $\mathrm{g}_{-} \mathrm{CN}_{\mathrm{x}} \mathrm{H}_{\mathrm{y}}$.
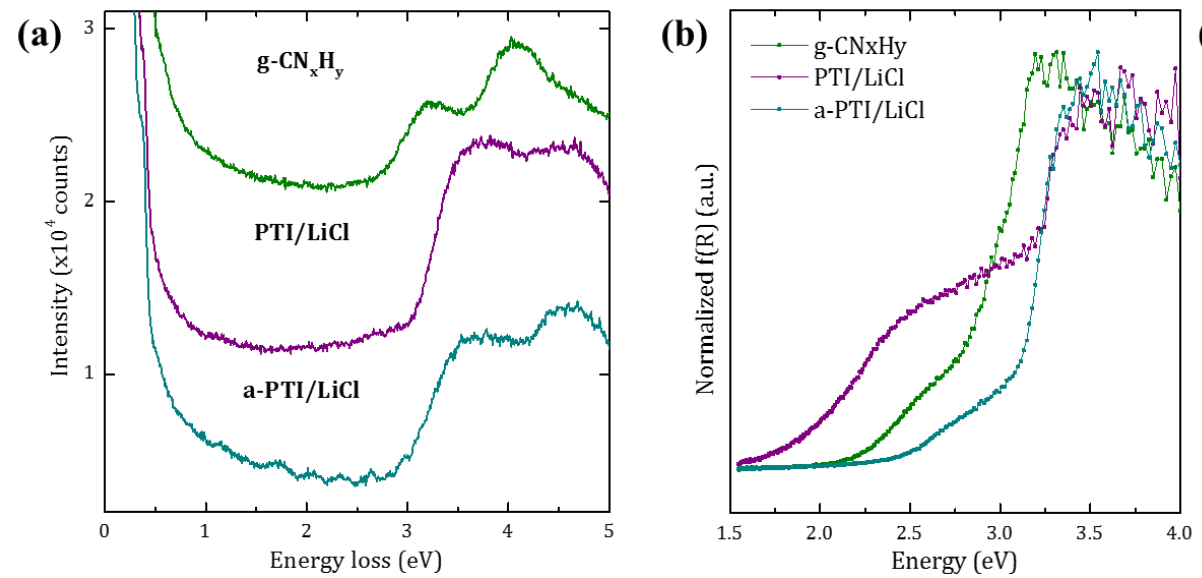

(c) Extrapolated bandgap energies
\begin{tabular}{|l|l|l|}
\hline Material & $\begin{array}{l}\text { Aloof-beam, } \\
\text { valence EELS }\end{array}$ & $\begin{array}{l}\text { UV/Vis } \\
\text { absorption }\end{array}$ \\
\hline g- $\mathrm{CN}_{\mathrm{x}} \mathrm{H}_{\mathrm{y}}$ & $2.68 \pm 0.02 \mathrm{eV}$ & $2.69 \mathrm{eV}$ \\
\hline $\mathrm{PTI} / \mathrm{LiCl}$ & $3.04 \pm 0.06 \mathrm{eV}$ & $3.07 \mathrm{eV}$ \\
\hline $\mathrm{a}-\mathrm{PTI} / \mathrm{LiCl}$ & $3.09 \pm 0.09 \mathrm{eV}$ & $3.06 \mathrm{eV}$ \\
\hline
\end{tabular}

Figure 2. (a) Characteristic valence EELS spectra for $\mathrm{g}-\mathrm{CN}_{\mathrm{x}} \mathrm{H}_{\mathrm{y}}, \mathrm{PTI} / \mathrm{LiCl}$, and amorphous $\mathrm{PTI} / \mathrm{LiCl}(\mathrm{a}-$ $\mathrm{PTI} / \mathrm{LiCl})$; spectra are shifted vertically for clarity. (b) Normalized UV-Vis absorbance, $\mathrm{f}(\mathrm{R})$, from the same materials. (c) Table summarizing the extrapolated bandgap energies from both spectroscopies. 